\title{
Low financial inclusion as an educational gaps result: the Republic of Moldova case
}

\author{
Victoria Cociug ${ }^{1 *}$, and Natalia Turcan-Munteanu ${ }^{2}$ \\ ${ }^{1}$ Researcher, associate professor, Institutul Naţional de Cercetări Economice, MD2012 I, Creanga 45, \\ Chisinau, Republic of Moldova \\ ${ }^{2} \mathrm{PhD}$ student, Academia de Studii Economice din Moldova, MD2012,Banulescu Bodoni 61, \\ Chisinau, Republic of Moldova
}

\begin{abstract}
Financial inclusion has a significant role in increasing the quality of life of citizens, as it represents the model of access to financial products and services in order to meet their development needs in a sustainable and responsible way. In this article, we are aiming to analyse the educational deficiencies of the Republic of Moldova, resulting in low financial inclusion of the population, as well as to provide certain solutions to increase the level of economic education of the population at different stages of the educational process. The opportunity to study this subject refers to the need to implement various solutions in order to ensure an acceptable level of financial inclusion, which primarily involves the participation of educational institutions in the formation of financial skills and financial literacy. In order to study the subject approached in the article, there were used the following research methods: analysis, synthesis, induction, deduction, comparison, etc. The research results include the selection from the literature of the concepts on financial inclusion, financial education and their importance for the economic development, research on this subject based on the analysis of the education system in the Republic of Moldova and the formulation of the most relevant research findings, resulting in recommendations for actions needed to be implemented actions needed to be implemented in the emerging countries, such as the Republic of Moldova in order to increase the level of financial inclusion.
\end{abstract}

\section{Introduction}

Financial inclusion is a major problem for societies in the process of evolution. The lack of awareness of the necessity, usefulness and, above all, the complexity of banking services becomes the key factor in discriminating access to quality finance, increasing credit risk and fraud in the process of procuring funds urgently by the low-income population. This has an impact on the financial system itself, which loses potentially solvent customers to dubious lending companies with excessive payments, and the population loses confidence in the financial system. This vicious circle does not contribute, on the contrary, distorts the

\footnotetext{
* Corresponding author: $\underline{\text { v_cociug@ @mail.ru }}$
} 
effort made by governance to ensure economic growth, reducing the consumption capacity of the population, but also that of financing small businesses in the early stages. The causes of low financial inclusion may vary from country to country, but the importance of this issue has led the World Bank to include it in its agenda, setting a goal that "adults, who are not currently part of the formal financial system, should have access to a trading account to store money, send and receive payments as a basic element to manage the financial life of global access to financial services by 2020" [1], considering the increase of the financial literacy of the population as a catalyst for the process of real improvement of the financial condition and living standards of the poor and disadvantaged. The concept of financial inclusion has emerged as an important topic on the global agenda for long-term sustainable economic growth and is considered a growing area of research interest for academics, policy makers, financial institutions and governments in developing countries $[2,3]$.

\section{Research methods}

Financial inclusion is one of the preconditions for a stable economic growth, being related to the public's ability to access financial intermediation services. In this context, any government shall set among its primary objectives, the objective of enhancing the financial inclusion (4), and this process must begin as early as the primary cycles of education.

In its simplest form, financial inclusion may be seen as the process of ensuring that people, in particular poor people, have access to basic financial services in the formal financial sector $[5,6]$. There are three arguments in the literature to integrate financial inclusion in the government development programs:

1. financial inclusion helps to improve the level of social inclusion in many societies [7];

2. financial inclusion can help in reducing poverty levels [8],

3. financial inclusion brings other socio-economic benefits $[9,10]$.

For this reason financial inclusion is considered to be a major strategy used to achieve the United Nation's sustainable development goals [11,12];

Financial inclusion as an object of study has had several approaches: the impact of financial inclusions on economic growth $[13,14$,$] , the relationship between financial$ inclusion and financial stability[15,16]); specific practices for some countries or regions regarding the development of financial inclusion $[17,18]$, increasing financial inclusion in the area of microfinancing and non-bank financing [19], the role of financial technologies in promoting financial inclusion [20,21]. However, the issue of financial education as a precondition for increasing the level of financial inclusion has not been sufficiently researched, due to its interdisciplinarity. Financial inclusion is often researched from the perspective of the financial products market, while financial education creates the demand for these products and refers to the field of education, which is analyzed by other social disciplines.

Thus, in order to study the subject approached in this article, there were applied the following research methods, such as:

a. analysis and synthesis of conceptual approaches to financial inclusion and financial literacy;

b. deduction and induction, in order to elucidate the factors influencing financial inclusions and financial education;

c. research on the situation in the Republic of Moldova on financial inclusion and financial education, analysing the data of the World Bank, PISA (OECD, 2018) and comparing it with those in neighboring countries in order to formulate conclusions and own opinions on solutions to increase financial inclusion by improving the quality of financial education for countries with an emerging economy. 


\section{Research results}

\subsection{Forming the concept of financial inclusion in the light of the demand and supply for financial products}

Financial inclusion is a state in which the population has access to a wide range of financial products and services that they can use at an affordable price and good quality and that meet their needs. Financial inclusion, as established by the World Bank concept [1], refers to efforts to make financial products and services accessible to all individuals and businesses, regardless of their net personal value or the size of the company. In the Bank's view, financial inclusion is aimed at removing barriers that exclude people from participating in the financial sector and using these services to improve their lives. This vision is made from the perspective of the financial system and refers to the granting of access to inclusive financing by financial institutions, especially banking ones.

Although there is no generally accepted definition, financial inclusion is usually assessed by three factors: access to financial services, use of financial services and quality of financial products. Together they play an important role in increasing the quality of life and educating and promoting well-being throughout society, having a causal impact on overall financial behavior. Referring to access, it happens in terms of possessing financial capabilities of the consumer/user of financial services, to be informed and able to make good decisions for their own financial movements for their purposes.

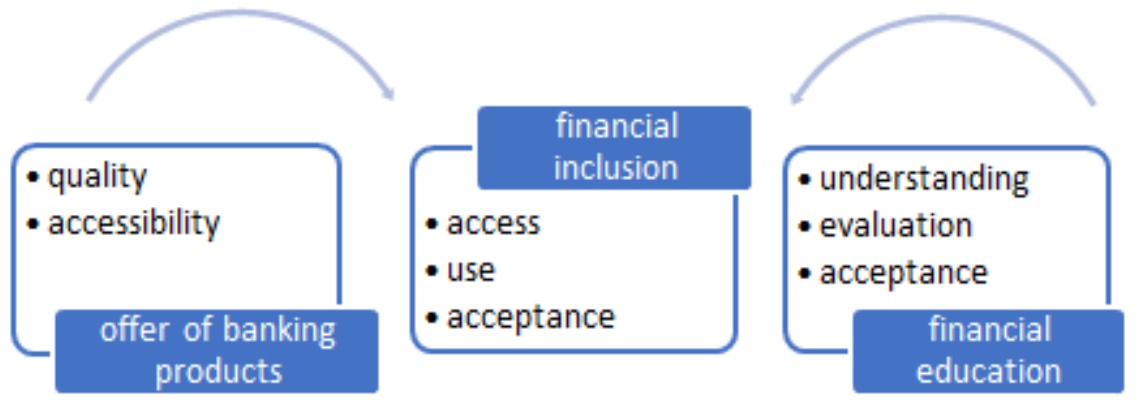

Fig. 1. The causal model of financial inclusion.

Improving financial inclusion can be largely achieved in the dimension of education, as financial education creates the demand for financial products and the first step in improving its level and can be ensured by developing financial knowledge, focusing on the use of financial services and products for needs and appropriate context, which has cultivated my interest in research in this field.

\subsection{Identifying financial education as a precondition for financial inclusions}

Financial education is recognized as a complement to the protection, inclusion, and regulation of financial consumers, as a way to improve individual decision-making and well-being, and as essential for financial stability and development. It conditions the demand for financial products, increasing financial inclusion. First defined in 1997 as "the ability of a person to use his knowledge and skills for the efficient management of financial resources for the purpose of lifelong financial security" [22] it refers to the ability of the individual to select from a multitude of products offered the appropriate ones for him. This definition is limited to "financial security" from the perspective of obtaining stable flows of 
money by the consumer of financial products, without taking into account the risk assumed by this flow. However, the inability to meet the financial obligations arising from the banking product is the most serious problem of the lack of solid financial knowledge for the population. This problem creates bankruptcies of small companies, the loss of the welfare of the population and, as a result, the loss of confidence in the ability of the financial product to ensure a better life. Thus, we consider the OECD's definition of financial education as "the process by which financial consumers and investors improve their understanding of financial products, concepts and risks and, through objective information, instructions and/or advice, develop skills, and confidence to become more aware of financial risks and opportunities, to make informed choices, to know where to go for help, and to take other effective actions to improve their financial well-being" (OECD, 2005). In this context, the application of the term financial education and could mean the knowledge of a financial product, the knowledge of financial concepts, the use of mathematical or computational skills to estimate flows such as financial planning, etc.[23].

Another concept encountered in the context of financial inclusion is financial literacy, which, in the opinion of Atkinson and Messy, is a combination of awareness, knowledge, skills, attitudes and behaviours needed to make sound financial decisions and ultimately to achieve an individual financial benefit."'[24]

In the context of studying the quality of financial education of young people, the OECD reformulates the definition in 2020, invoking both knowledge and skills to apply them: Financial literacy is knowledge and understanding of financial concepts and risks, and the skills, motivation and confidence to apply such knowledge and understanding in order to make effective decisions across a range of financial contexts, to improve the financial wellbeing of individuals and society, and to enable participation in economic life. [25].

In our opinion, financial education is the process of forming in the individual a conscious financial behaviour, from the perspective of which the options financial products will bring maximum utility with a minimum associated risk. In this context, that process may include, but is not limited to:

1. Financial literacy as part of financial education which refers to the acquisition of knowledge necessary to form one's own investment opinion.

2. Cognitive skills, which are based on how to analyse, compare, select, and finally identify the optimal product

3. Behavioural model, which includes the ability to decide on a product based on how and the capacity to perceive financial information

4. Emotional behaviour, which aims at the speed of the decision to purchase the product

5. Dependence on the opinion of society and exposure to social factors, which impose certain financial needs depending on the environment in which the individual operates.

All the components listed above form the financial culture, which is the result of financial education and which includes the development of knowledge, skills and character of individuals who have the ability to act (i.e. to have knowledge) and as an opportunity to act (availability of products). If the first two refer strictly to the formation of knowledge according to the cognitive capacity of the individual, the last three are behavioural and form his attitude towards the financial product, but all depend on the quality of financial education, which, according to the OECD, should be seen as a process that takes place throughout life, in development and continuously, especially to take into account the increased complexity of markets, the changing needs at different stages of life and increasingly complex information.

Financial education must focus on key objectives that can be implemented in different strategic directions of action, starting both from the need to increase the level of consumer protection and from the need to improve the level of financial capability and the degree of 
financial inclusion. Financial inclusion is the concept by which individuals and businesses have access to useful and affordable financial products and services that meet their needs.

\subsection{Analysis of financial education and inclusion in the Republic of Moldova}

According to the Findex report ${ }^{\dagger} 2017$, globally, $69 \%$ of adults have an account, which gives adults access to an important financial instrument. In advanced economies (with high incomes), $94 \%$ of adults have an account, ranging from $64 \%$ in Uruguay to $100 \%$ in countries such as Australia, Denmark and the Netherlands. In developing economies (low or medium income) the share of the population with access to an account is 63 percent.

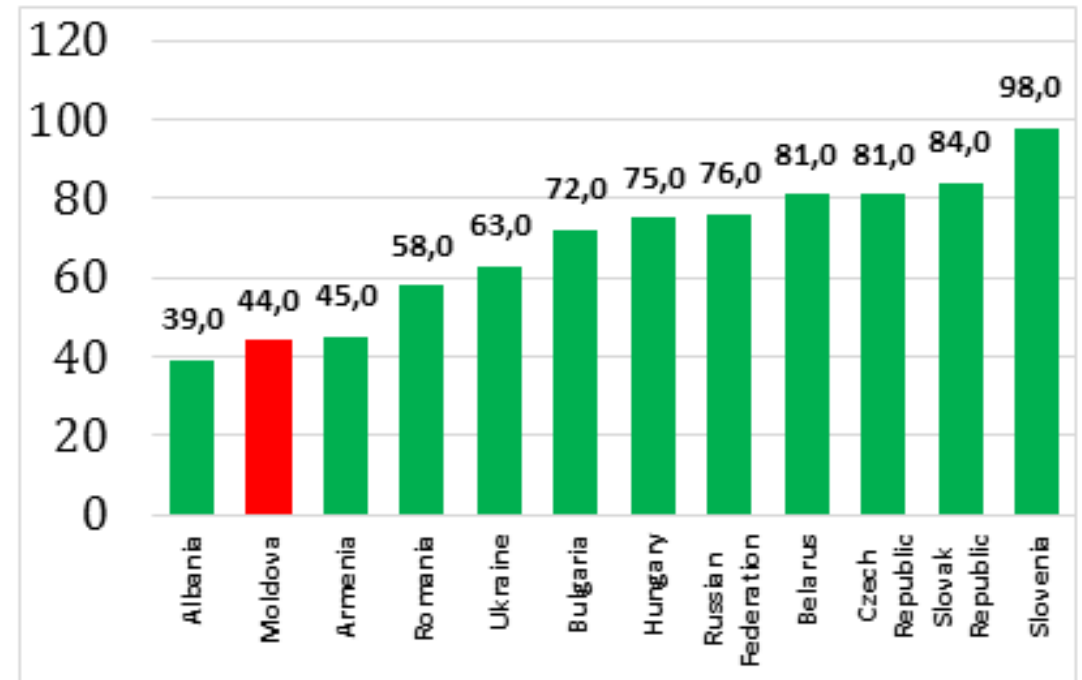

Fig. 2. Level of financial inclusion of the Republic of Moldova.

Low financial inclusion in emerging countries is conditioned both by low financial education, which forms a similar demand for banking products, and by the limited supply of financial products. The Republic of Moldova is no exception, facing a very low level, with an indicator of about $44.0 \%$ of the population having a payment account opened with a financial institution. According to the data illustrated in Chart 2, in Europe this figure places the country at the end of the ranking. The distribution of these accounts by population categories (Figure 3) illustrates that the problem of low demand for banking products is due to financial education.

\footnotetext{
†The World Bank's Global Findex database is the world's most comprehensive set of data on how adults save, borrow, make payments and manage risks
} 


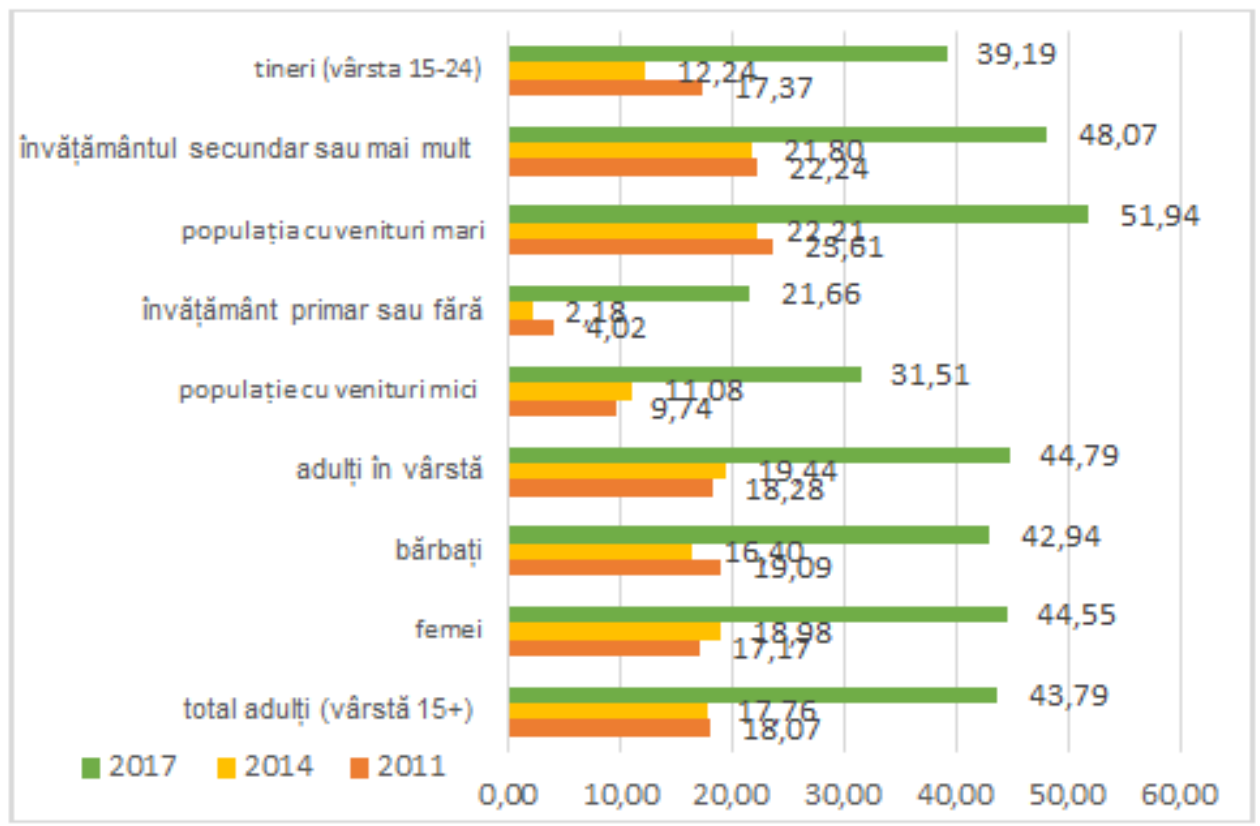

Fig. 3. Distribution of possession of bank accounts by population categories.

Thus, only $39.19 \%$ of the young people, aged between 15 and 25 , have a payment account, and this figure includes students, to whom higher education institutions open accounts to transfer the scholarship amounts. Among the categories with a higher average weight (about $44 \%$ ) of adults who have access to an account are those with secondary or higher education (48.07\%), with high incomes (51.94\%), but also elderly adults. The situation is explained by the fact that people with higher education have a job in state institutions or large international corporations, with a salary officially paid, usually by card. The same reasoning is for adults, who have opted for the receipt of the pension by card or who are maintained by remittance via transfers, also made by card. Although the situation during the three periods in which the observations were made $(2011,2014,2017)$ improved, the financial inclusion increasing from $18.03 \%$ in 2011 to $43.79 \%$ in 2017 , the problem of low financial education remains acute and denotes a huge gap in primary education. Thus, only $21.66 \%$ of the population in this category have an account, and in 2014 this figure was $2.18 \%$.

In the Republic of Moldova, the main factors that contribute to maintaining a low degree of financial inclusion, in some places interdependent, are:

- Insufficient attention to the needs of the user-consumer

- False perceptions of users about product features, about costs;

- Lack of knowledge of rights and obligations;

- Low level of banking;

- The high share of the informal economy and the low standard of living;

- The low degree of adaptation of the financial services offers to the needs of the population;

- Limited awareness and financial illiteracy;

- Low rate of financial education in the Republic of Moldova, of about $27 \%$ of the adult population;

- The tendency to use consumer loans; 
- Access to informal loan sources ( $38 \%$ of the population);

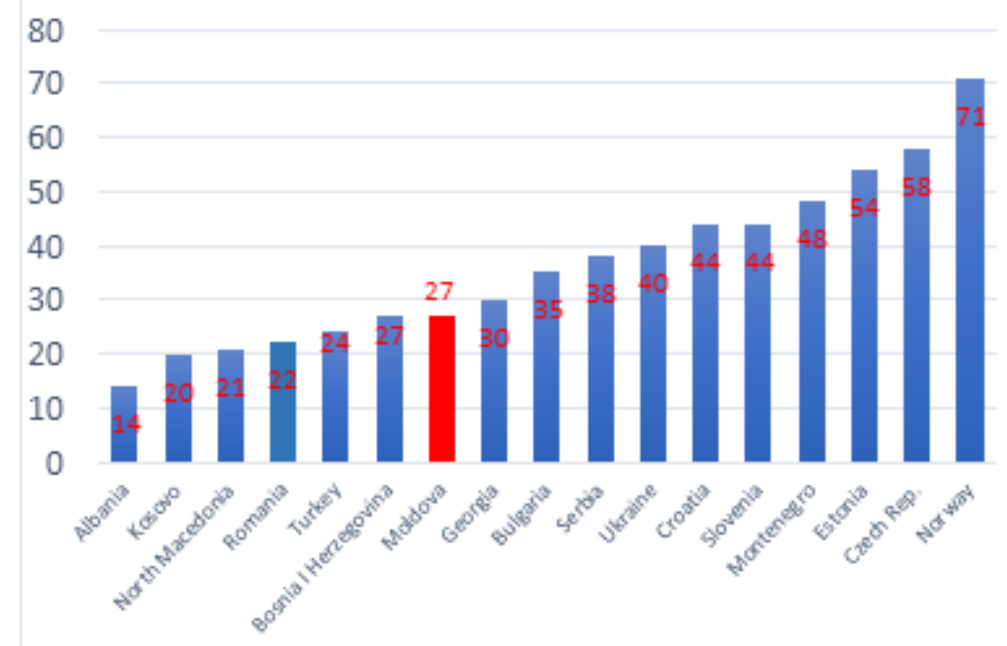

Fig. 4. Share of financially literate population, $\%$ (2017) in the Republic of Moldova.

All these raise the issue of skills, abilities and necessary knowledge formed early in school, high school, academia, but also the issue of adapting curricula to the needs of the population, employers and public authorities.

Although efforts have been made in the Republic of Moldova to create an early financial education framework by designing in 2012 an optional subject "Social and financial education" in schools for classes V-IX, which aims to form a sound economic vision and create a competent money management plan among young people, but the number of students involved in the program is small. Discipline is, unfortunately, optional and refers to the Recommendation of the European Parliament and the Council of the European Union on key competences from a lifelong learning perspective, which outlines a "European training profile" for compulsory education graduates. However, the discipline is quite complex and puts a big and quite confusing burden on the student, initiating him in both social and financial problems at the same time. At the same time, the concept of financial product and the risks it entails is presented in an extremly vague way, limited only to the sub-competence of recognizing consumer rights and how they can exercise them in relation to the bank in the VII-th grade, and the application of knowledge to banking products in solving loan situations for pupils of the VIII-th grade. And this is in the context when, at least in Romania, this discipline is taught in the III-rd and IV-th grades only with an emphasis on finance. After all, this is the explanation for the extremely low figures for the financial inclusion of the population with primary education.

Analyzing local circumstances, one perspective in this regard is that of continuing financial learning and education and supporting early financial education.

\section{Solutions for efficient and sustainable financial inclusion}

As mentioned above, an adequate financial culture is the result of several factors, the most important of which is the appropriate level of financial literacy. The diversification of the financial knowledge of the population cannot be carried out without the co-optation in the process of education of the suppliers of financial products and the creation of a system of 
relations between them and consumers. This can ensure the availability of information about financial products and their producers as well as the opportunity for the consumer of financial services to apply and test relevant information, perform calculations, analyze financial and business risks, to have the ability to identify the advantages and disadvantages of the used financial services.

In this context, we come up with some solutions for increasing the level of financial education of the population of the Republic of Moldova, which, we hope, will be found useful for other states with an emerging economy: The main ways identified to provide efficient financial education are:

1. Establishment of an institutional mandate

Establishment of a clear mandate to facilitate the implementation of financial inclusion policies, as a coordinator between institutions developing various programs that support the purpose of increasing financial education, which would make it easier and establishment of clear responsibilities that, made public, would also increase the awareness and protection among the population.

2. Modification of school, high school, university programs

Responsibility of the Ministry of Education for the development of a national curriculum that provides economic education, which will include the financial sectors (banking, capital market, insurance, etc.) and institutional roles - licensing, supervision and consumer protection. Gaining a basic knowledge of financial terms and concepts is a prerequisite for individuals and families to make good decisions about managing their financial resources, as well as the concepts of saving, payments, loans, investments, risk management.

\section{$\underline{\text { 3. Institutional arrangements }}$}

Developing collaborations between public institutions and the private environment, in order to provide practical experience and corroborate theoretical knowledge, so that pupils, students can expect consistent and reliable information. It is important to support these participations by both teachers and employers in the roles of public institutions or private media.

\section{Lifelong financial education}

Encouraging decision-makers in the authorities to develop internal educational programs in the workplace. Structural promotion of financial skills in academia, among employees

5. Allocation of resources - human, technological, with a focus on financial education, for appropriate vocational training in schools, high schools and to improve access to tools that help pupils, students and families to understand the role of financial inclusion and the support offered to them and its implications.

6. Promotion of interactive learning

Development of educational economic programs by conducting regular lectures for the general public, organizing economic conferences on various topics.

7. Facilitating access to information and education by creating communication campaigns in various sectors and creating portals with important references for the community to respond to the economic problems they face.

Establishment of a website administered by a public institution, with references to financial regulators, advice and information resources.

\section{Conclusions}

Financial inclusion is an important precondition for ensuring economic growth, as it allows access to financial products and services through which the low-income and vulnerable population is placed in the economic circuit by increasing consumption capacity or 
obtaining a chance to finance or start a small business. With the increase in financial inclusion, the communities gain, as they grow economically and new jobs are created. Education is also becoming more accessible and the population is becoming more informed, while the financial education, which goes hand in hand with financial inclusion, will allow the population to access saving tools. The lack of access to financing of some important social categories is a failure of the financial market. Financial exclusion is not the only consequence of it, financial exclusion leading to the more difficult phenomenon to solve, that of social exclusion.

\section{References}

1. World Bank, UFA, 2020 Overview: Universal Financial Access by 2020, https://ufa.worldbank.org/

2. Allen. F., Demirguc-Kunt, A., Klapper, L.,\& Peria Martinez, S.M. (2012). The foundations of financial inclusion understanding ownership and use of formal Accounts. Policy Research Working Paper 6290, World Bank, Washington, https://spiral.imperial.ac.uk/bitstream/10044/1/39804/2/Financial\%20Inclusion_06Jan1 6-JFI_Resubmission.pdf

3. Amidzic, G., Massara, A., \& Mialou, A. (2014). Assessing countries' financial inclusion standing - A new composite index. IMF working paper WP/14/36. https://www.imf.org/external/pubs/ft/wp/2014/wp1436.pdf

4. Arun, T., \& Kamath, R. (2015). Financial inclusion: Policies and practices. IIMB Management Review, 27(4), 267-287. http://doi.org/10.1016/j.iimb.2015.09.004

5. Allen, F., Carletti, E., Cull, R., Qian, J. Q., Senbet, L., \& Valenzuela, P. (2014). The African financial development and financial inclusion gaps. Journal of African economies, 23(5), 614-642.

6. Ozili, P. K. (2018). Impact of digital finance on financial inclusion and stability. Borsa Istanbul Review, 18(4), 329-340

7. Bold, C., Porteous, D., \& Rotman, S. (2012). Social cash transfers and financial inclusion: Evidence from four countries. Consultative Group to Assist the Poor, No. $77,1-28$

8. Neaime, S., \& Gaysset, I. (2018). Financial inclusion and stability in MENA: Evidence from poverty and inequality. Finance Research Letters, 24, 230-237.

9. Sarma, M., \& Pais, J. (2011). Financial inclusion and development. Journal of international development, 23(5), 613-628.;

10. Kpodar, K., \& Andrianaivo, M. (2011). ICT, financial inclusion, and growth evidence from African countries (No. 11-73). International Monetary Fund Working Paper, $\mathrm{WP} / 11 / 73$.

11. Sahay, R., Čihák, M., N'Diaye, P. M. B. P., Barajas, A., Mitra, S., Kyobe, A., ... \& Yousefi, S. R. (2015). Financial inclusion: can it meet multiple macroeconomic goals? IMF Staff Discussion Notes, No. 15/17, 1-33. Washington, DC: International Monetary Fund.;

12. Demirguc-Kunt, A., Klapper, L., \& Singer, D. (2017). Financial inclusion and inclusive growth: A review of recent empirical evidence. The World Bank. Policy Research Working Paper, No 8040, 1-25.

13. Kim, D. W., Yu, J. S., \& Hassan, M. K. (2018). Financial inclusion and economic growth in OIC countries. Research in International Business and Finance, 43, 1-14. 
14. Mohan, R. (2006). Economic growth, financial deepening, and financial inclusion. Dynamics of Indian Banking: Views and Vistas, 92-120,

15. Hannig, A., \& Jansen, S. (2010). Financial inclusion and financial stability: Current policy issues. Asian Development Bank Institute Working Paper, No. 259, 1-29.;

16. Cull, R., Demirgüç-Kunt, A., \& Lyman, T. (2012). Financial inclusion and stability: What does research show? Consultative Group to Assist the Poor, 71305, 1-3

17. Fungáčová, Z., \& Weill, L. (2015). Understanding financial inclusion in China. China Economic Review, 34, 196-206;

18. De Matteis, L. (2015). Financial inclusion, policies and instruments for migrants in Italy. Savings and Development, Special Issue, UMM Master Awards, 38-69.

19. Ghosh, J. (2013). Microfinance and the challenge of financial inclusion for development. Cambridge journal of economics, 37(6), 1203-1219.;

20. Gabor, D., \& Brooks, S. (2017). The digital revolution in financial inclusion: international development in the fintech era. New Political Economy, 22(4), 423-436

21. Ozili, P. K. (2019). Blockchain Finance: Questions Regulators Ask. Disruptive Innovation in Business and Finance in the Digital World (International Finance Review, Vol. 20), Emerald Publishing Limited, 123- 129;

22. Marcin Kawiński \& Piotr Majewski, (2017) "Financial and insurance literacy in Poland," Working Papers 2017-03, Faculty of Economic Sciences, University of Warsaw . https://ideas.repec.org/p/war/wpaper/2017-03.html

23. SHERRADEN, M. S. (2010). Financial capability: What is it, and how can it be created? Working Paper, 2010, no.10-17. Washington University in St. Louis. https://openscholarship.wustl.edu/cgi/viewcontent.cgi?article=1643\&context=csd_rese arch

24. Atkinson şi Messy, (2012). Atkinson, A. and F. Messy (2012), "Measuring Financial Literacy: Results of the OECD / International Network on Financial Education (INFE) Pilot Study", OECD Working Papers on Finance, Insurance and Private Pensions, No. 15, OECD Publishing, Paris, https://dx.doi.org/10.1787/5k9csfs90fr4-en.

25. OECD (2020), PISA 2018 Results (Volume IV): Are Students Smart about Money?, PISA, OECD Publishing, Paris, https://doi.org/10.1787/48ebd1ba-en. ISBN 978-9264-72845 -5 (pdf). 